\title{
CONFINS POÉTICOS:
}

\section{Contemporaneidade e romantismo na poesia finlandesa}

\author{
Carolina Alves MAGALDI ${ }^{65}$
}

\begin{abstract}
RESUMO: O movimento romântico foi de fundamental importância para a constituição do estado nacional finlandês, principalmente devido à publicação de seu épico nacional, a Kalevala. Nesse artigo procuramos estabelecer um paralelo entre as raízes românticas da literatura finlandesa e a produção contemporânea de um de seus maiores expoentes, Juhana Vähänen, por meio da análise de seu poema Alan Turing.
\end{abstract}

PALAVRAS-CHAVE: Poesia finlandesa; Romantismo; Contemporaneidade; Kalevala; Juhana Vähänen.

ABSTRACT: The Romantic Movement was of key importance in the shaping of the Finnish national estate, mainly due to the publishing of its national epic, the Kalevala. In this essay we aim to establish a connection between the Romantic roots of the Finnish literature and the contemporary output of one of its greatest names, Juhana Vähänen, by means of an analysis of his poem Alan Turing.

KEYWORDS: Finnish poetry; Romanticism; Contemporary; Kalevala; Juhana Vähänen.

A Finlândia é um país pouco conhecido por estrangeiros em geral. O romancista Mika Waltari, um dos poucos escritores finlandeses a ser reconhecido internacionalmente, inicia seu romance histórico $O$ aventureiro com a seguinte afirmação:

Nasci e fui criado numa região longínqua que os cosmógrafos chamam Finlândia, um país lindo e extenso, mas que muita gente instruída desconhece. Os meridionais imaginam que uma terra situada assim tão ao Norte deve ser gélida e inadequada à habitação humana e que os que vivem acolá são selvagens que se vestem com peles de animais ferozes e vivem escravizados ao paganismo e à superstição. Tal idéia não podia ser mais absurda. (WALTARI, s/d, p.7).

\footnotetext{
65 Programa de Pós-Graduação em Estudos Literários (Doutoranda; bolsista CAPES). Universidade Federal de Juiz de Fora (UFJF) - Juiz de Fora - MG - Brasil - carolina_magaldi@ hotmail.com
} 
Neste artigo pretendemos traçar um paralelo entre a Kalevala, maior obra literária romântica do país, publicada em 1839, e a poesia contemporânea finlandesa, representada aqui por Juhana Vähänen. Para compreendermos tal conexão precisamos, primeiramente, abordar brevemente alguns pontos-chave da história do país, com ênfase para o início do século XIX e o final do século XX.

A inserção finlandesa no discurso de representação histórica se dá no século VI, quando os suecos realizam uma expedição para identificar locais propícios para a pesca. A dominação sueca é oficializada no século XII e permanece até meados do século XVIII. Durante esse período a Finlândia foi mantida como província, com existência política limitada. O único esforço para urbanização e construção de uma infraestrutura educacional foi feito no século XVII por Per Brahe, nobre sueco hoje imortalizado em uma estátua no centro de Turku, a primeira capital finlandesa.

O final do período de dominação sueca representou, para os finlandeses, o início de um contexto de colonização ainda mais conturbado. Napoleão Bonaparte, em um esforço para pressionar os suecos a apoiarem o boicote comercial à Grã-Bretanha, leva a Rússia a invadir a Finlândia como forma de atacar a coroa sueca indiretamente.

Sem grandes interesses no território finlandês, os russos iniciam sua dominação de forma autoritária, mas com a chegada de Alexandre II ao governo as técnicas liberais do novo czar ganham espaço. Esse foi o período de maior autonomia política finlandesa até então, contando, inclusive, com um parlamento próprio, e foi marcado pela formação de um ideal protonacionalista entre os finlandeses.

Ao final do século XIX as turbulências internas na Rússia levam ao retorno de formas mais restritivas e autoritárias de governo. Os consequentes esforços para se libertar do poderio russo, entretanto, só se concretizam com a independência política finlandesa em 1917, quando da revolução bolchevique.

O momento de independência política é seguido por uma guerra civil entre os brancos, partidários do capitalismo, e os vermelhos, de filiação socialista. Os brancos vencem a longa guerra, porém o período de paz mais uma vez é curto.

Durante a Segunda Guerra Mundial, período em que o país era ainda largamente agrário, a Finlândia trava uma batalha particular contra os russos, na chamada Guerra do Inverno. Os finlandeses têm extremo orgulho de terem sido o único país invadido, mas não ocupado pelo exército vermelho, e destacam as batalhas dos 105 dias da invasão 
russa como uma guerra à parte, talvez para se distanciarem da realidade de que fizeram parte do eixo nazista durante o conflito global.

A aliança com a Alemanha fez com que a Finlândia não se qualificasse para a ajuda do Plano Marshall e precisasse pagar uma pequena fortuna em indenizações de guerra. Esse esforço fez com que o país se industrializasse rapidamente, culminando com a associação à tecnologia de ponta que fazemos hoje.

Geograficamente, a Finlândia situa-se entre a Europa ocidental e a oriental, em um território isolado étnica, cultural e linguisticamente. $\mathrm{O}$ isolamento étnico se dá por sua ligação com os húngaros caucasianos em uma região maciçamente ariana. Já o distanciamento linguístico-cultural é sentido principalmente na língua finlandesa, que nem sequer é indo-europeia, e reforçado pela tentativa de não se ter palavras semelhantes a nenhuma língua estrangeira. Mesmo no caso de vocábulos ligados à informática, por exemplo, emprestados da língua inglesa na maioria das línguas ocidentais, os finlandeses optaram por utilizar denominações derivadas de termos locais. Dessa forma, o termo computador é chamado por lá de tietokone, ou máquina de pensar.

O primeiro momento histórico crucial para compreendermos a poesia finlandesa se dá no início do século XIX. Esse período foi marcado por uma mentalidade protonacionalista, representada na frase-chavão "suecos não somos, russos não queremos ser, sejamos, então, finlandeses". A tentativa de se criar uma identidade nacional passou, no caso finlandês, pela criação de um texto literário, a Kalevala, que incorporasse as referências populares nacionais e compensasse sua ausência de fatos históricos gloriosos, de uma monarquia e até mesmo de uma identidade política.

A escolha de um poema épico organizado a partir de canções e narrativas populares refletiu os ideais românticos que buscavam ligar a legitimação nacional às mitologias populares e línguas vulgares, alcançando assim uma unidade utópica entre povo, língua e nação.

O esforço de coleta e organização do poema foi fundamentado, dessa forma, por um Romantismo tardio, baseado nas teorias do alemão Johann Gottfried von Herder. Como afirma a estudiosa francesa Pasquale Casanova, 
da literatura", como escreve já em seus Fragmentos de 1767 -, antagônica à definição aristocrática francesa predominante, revoluciona a noção de legitimidade literária e consequentemente as regras do jogo literário internacional. Ela supõe que o próprio povo sirva de conservatório e de matriz literários, e portanto que se pudesse a partir de então avaliar a "grandeza" de uma literatura pela importância ou pela "autenticidade" de suas tradições populares. (CASANOVA, 2002, p.102-103).

Herder, dessa forma, redefine o mapa literário europeu ao oferecer uma forma de legitimação nacional não classicista e não galicista, baseada em suas culturas populares, fato que fez suas teorias se tornarem extremamente populares na periferia europeia.

Assim, a Sociedade Finlandesa de Literatura é fundada em 1831 para possibilitar a escrita da Kalevala; tendo sido, portanto, inaugurada antes da publicação da primeira obra em língua finlandesa. O processo de coleta de poemas populares, realizado por Elias Lönnrot é registrado pelo próprio compilador em crônicas submetidas ao principal jornal de Helsinque e no prefácio do épico, publicado antes do restante da obra. A necessidade política da Kalevala leva a uma publicação inicial do poema em 1839, sendo que a versão hoje lida e traduzida da epopeia foi trazida ao público dez anos mais tarde, da forma como o autor pretendia.

A Kalevala narra as desventuras de três magos, Väinämöinen, Ilmarinen e Lemminkainen, que forjam um objeto de extremo poder, o sampo, o perdem e passam a percorrer todo o território que hoje é a Finlândia na tentativa de recuperá-lo, destruí-lo, e assim restaurar o bem comum.

Georg Lukács, filósofo e teórico literário húngaro, associa a epopeia à totalidade de sociedades fechadas. As narrativas homéricas, únicas epopeias verdadeiras na visão do autor, conteriam, assim, todas as respostas e nenhuma pergunta. O nascimento da lírica, por outro lado, teria introduzido a individualidade à literatura e o surgimento da filosofia teria trazido as perguntas, quebrando a unidade das respostas e fazendo com que as epopeias perdessem seu lugar na evolução da grande épica.

Para o autor houve, no movimento romântico, um esforço pela construção de épicos nacionais baseados em narrativas folclóricas e contos medievais. Lukács destaca o exemplo da obra alemã $O$ anel dos Nibelungos, que para o filósofo é um "belo erro", representando "o desesperado esforço de um grande escritor para salvar a unidade épica 
de um assunto verdadeiramente épico - unidade essa que se desintegra num mundo modificado" (LUKACS, 2007, p.54).

O esforço pela representação da totalidade via obras literárias é pertinente ao movimento romântico, marcado pela busca da essência por meio das emoções individuais e gloriosas conquistas coletivas. Uma das formas dessa busca se deu por meio de voltas ao passado embasando a construção de ideais utópicos:

Outra característica geral da corrente restitucionista é que seus representantes mais notáveis são em sua maioria literatos. Se ela se expressa também na filosofia (Novalis) e na teoria política (Adam Muller), por exemplo, não é menos verdade que foram principalmente artistas que tiveram afinidades com tal visão. Parece-nos que a predominância de artistas se explica sobretudo pela evidência crescente do caráter irrealista, até mesmo irrealizável da aspiração à restituição de um período do passado perdido para sempre. O sonho do retorno à Idade Média (ou a uma sociedade agrária) tem, no entanto, um grande poder de sugestão no plano da imaginação e se presta a projeções visionárias. Ele atrairia, portanto, primeiramente, as sensibilidades que se orientam para a dimensão simbólica e estética. (LÖWY \& SAYRE, 1993, p.42).

No caso finlandês, a tentativa utópica de trazer unidade a um território politicamente dominado, isolado de seus vizinhos por parâmetros étnicos, linguísticos e culturais e recortado por milhares de lagos e ilhas foi sistematizada pela Kalevala.

O poema épico permeia a sociedade finlandesa desde então, tendo um feriado próprio, celebrado em 28 de fevereiro, representações em praças e anfiteatros acadêmicos e tendo sido revisitado na literatura do dramaturgo e romancista Alexis Kivi, nas artes plásticas de Gallen-Kallela, além de recriações em prosa e traduções para mais de quarenta línguas.

O segundo momento histórico que devemos enfatizar distancia-se do primeiro por cerca de 150 anos. O início da década de 1990 traz uma mudança fundamental para a história finlandesa, período esse marcado pelos movimentos globalizatórios, inaugurando uma era de tecnologia e abertura para o mundo exterior. Nesse momento o país ingressa na União Europeia e passa a conviver com outras etnias e culturas dentro de seu próprio território a partir do primeiro movimento migratório de sua história, proveniente da Somália e do Vietnã em meados da década em questão. ${ }^{66}$

\footnotetext{
${ }^{66}$ Virtual Finland. Disponível em http://web.archive.org/web/20080420130905/http://virtual.finland.fi/
} 
Essas condições propiciam riquezas culturais e financeiras, culminando com a escolha do país como melhor nação para se viver pela revista estadunidense Newsweek em agosto de 2010, representando a validação ocidental que a Finlândia tanto almejou ao longo de nove séculos de dominação política.

A busca pela essência e a unidade totalizante se manteve presente na literatura finlandesa desde seu início grandiloquente com a Kalevala. Essa essência, entretanto, passa a ser buscada na era pós-globalização por meio de demandas individuais e de diálogos com a tecnologia, revelando características culturais que permaneceram disfarçadas nos esforços românticos representados na Kalevala.

Juhana Vähänen, jovem poeta finlandês, representa com maestria as características da nova geração literária finlandesa. Ele é editor da revista Tuli\&Savu, dedicada à poesia de sua geração e publica ainda em um blog particular, o $\underline{\text { BigSur ja }}$ Surreal. Seu primeiro volume de poesias, Cantorin pölyä, foi publicado em 2005, com grande destaque de público e da crítica especializada.

A obra parte de dois personagens históricos, o cineasta russo Sergei Eisenstein e o matemático inglês Alan Turing para discutir a realidade finlandesa e a estrutura de sua peculiar língua. $\mathrm{O}$ apreço às questões linguísticas faz com que muitos teóricos considerem Vähänen como parte do movimento de materialismo linguístico, originado nos Estados Unidos com o grupo L-A-N-G-U-A-G-E e dedicado a manipulações da linguagem para melhor expressar e, muitas vezes, distorcer o mundo exterior às palavras.

Juhana Vähänen apresenta seu gosto pelo materialismo linguístico por meio principalmente de jogos de palavras. Sua segunda obra tem como título Avaa tule, que pode ser traduzido como abra ou venha, mas apresenta imensa semelhança com avaan tulen, que significa abrirei fogo, combinando assim posições simultâneas de abertura e agressividade. Essa característica é amplamente cultivada por falantes da língua finlandesa. O slogan representativo de Turku, antiga capital finlandesa eleita como capital cultural da União Europeia em 2011 lê Turku palla, um trocadilho entre Turku está de volta e Turku pega fogo, referência mordaz ao fato de o incêndio de 1828 ter custado à cidade seu status de capital nacional.

netcomm/news/showarticle.asp?intNWSAID=25787. Acesso em 15 de fevereiro de 2011. 
O poema que analisaremos chama-se exatamente Alan Turing, referência ao matemático inglês nascido em 1912 e falecido em 1954, considerado o pai da inteligência artificial. $O$ trabalho de Turing foi de fundamental importância para o Império Britânico ao longo da Segunda Guerra Mundial ao desenvolver criptografias que possibilitaram a comunicação entre as tropas aliadas e a quebra dos códigos nazistas.

O destaque trazido por seu trabalho, entretanto, gerou um indesejado interesse em sua vida particular e o matemático homossexual acabou sendo submetido a tratamentos hormonais como forma de castração química para evitar a prisão, uma vez que a homossexualidade era ilegal na Grã-Bretanha de sua época.

Turing morreu em 1954 por envenenamento por cianureto, que sua família insiste não ter sido suicídio. Em 2009 o governo britânico pediu desculpas públicas a sua família pela forma como o gênio matemático foi tratado no período pós-guerra. ${ }^{67}$

O poema parte da referência histórica de Alan Turing para problematizar questões próprias dos finlandeses, com relação a sua cultura e estrutura social. Na Finlândia se busca individualismo a qualquer preço, sendo que é praticamente impossível encontrar uma mesa em restaurantes ou cafés para mais de duas pessoas, e normalmente ocupadas por uma. Há, até mesmo, uma lenda urbana segundo a qual um homem teria cometido assassinato ao descobrir que havia outra casa sendo construída na ilha em que passava seus verões.

Para analisarmos as relações entre a gênese poética romântica da Finlândia e a obra de Juhana Vähänen optamos, inicialmente, pela tradução integral de seu poema Alan Turing realizada pela autora, motivada pela pouca visibilidade do poeta e de sua obra.

\author{
Alan Turing \\ meu nome é Alan Turing tenho 14 anos \\ um albatroz está circulando sobre mim a dois mil metros \\ no ar eu não sei quem eu lembro às pessoas \\ minha mãe me lembra de amarrar os cadarços \\ o mundo é feito de um infinito número de responsabilidades \\ e estupidezes o cachimbo de meu pai me lembra \\ das viradas e reviradas da linguagem as coisas que entendemos
}

\footnotetext{
${ }^{67}$ BBC. Disponível em: http://news.bbc.co.uk/2/hi/technology/8249792.stm. Acesso em 11 de fevereiro de 2011.
} 
as plantas crescem em direção à luz eu cresço

em direção à luz as plantas viram e reviram Alan Turing vira e revira amarram cachos em torno dos pescoços dos inocentes o mundo é

meu nome é Alan Turing tenho 21 anos

é um número sagrado eu sou sagrado

as figuras na minha gravata estão vivas eu tenho um globo

em miniatura no bolso do meu paletó eu posso ver tudo

do alto do meu pilar eu fico lá como um louco

a agulha apontando a verdade final

é que não há eu não sei o que a verdade

final é vinho é para os burros

ele entorpece a linguagem ele entorpece a mente apesar de somente necessário

para a imitação da linguagem um jogo tolo

como todo o resto que está errado

eu não gosto de cachorros não gosto de outras pessoas

meus pais não são pessoas eles são parte de alguma coisa

a mais eles não existem

plantas congeladas revelam suas veias meu quarto

é a casa do sol meu quarto meus livros

meus diagramas estão em minha mente a mente é tudo e cérebro

eu vivo para o cérebro o cérebro sou eu e eu sou o cérebro

números são lindas letras eu sou

meu nome é Alan Turing tenho 28 anos

eu vi uma mulher assim mesmo

numa livraria que pena eu não ser mulher

não que isso signifique alguma coisa

eu apodreço maçãs em um vaso os rostos finos de meninos de coral

o mosaico de azulejos brancos do claustro

micro fraturas o significado de tudo

talvez pegar emprestado um guarda-chuva e escapar

da vida da chuva o formato da semente é um olho

o formato do olho é a base de tudo suspiros

fazem o mundo o mundo sucumbe como um castelo de cartas

e tudo explode o olho explode e o corpo vítreo filtra

no belo rosto si em seu belo rosto

si a lógica é um espelho espelhos estão doentes os doentes são agradáveis

posso ver o futuro e ele não me agrada

apesar de ter três metros de altura oh eu não quero esquecer

o mundo que me criou

eu quero esquecer o tempo

meu nome é Alan Turing tenho 35 anos

si eu tenho uma memória acústica

no topo do pilar

não os agrada as figuras em fluxo

no deserto um rato se ajoelha ao altar

um rato acústico com seu rabo máquinas inteligentes 
querendo ser ratos isso é um pensamento

é uma máquina eu não gosto de outras pessoas

imitando ratos ruínas corujas

a guilhotina desce em suas asas antes do livro nove nas sepulturas

as câmaras de eco nos bicos fluem

o mar divide mistério de xadrez e um único

significado que é tudo é uma máquina é um pensamento

que é uma máquina que é um pensamento

meu nome é Alan Turing tenho 42 anos

os olhos do falcão são cobertos

ambos os lados da face desaparecem

um no outro na pele

o véu do papiro lê o grito do falcão

é meu grito se espalhando como

um enxame e fragmentos de hordas de baleias

as colagens de um velho piano

abstrações flutuam na visão minhas memórias de máquinas

fase de quebra de código percepção ação pensamento

os olhos do falcão contêm memórias do mundo

uma sequência acústica na menina dos olhos

ligações acústicas unidas

$\mathrm{si}^{68}$

\footnotetext{
${ }^{68}$ No original: nimeni on Alan Turing olen 14 / albatrossi kiertelee ylläni noin 2000 metrin / korkeudessa en tiedä ketä muistutan / äitini muistuttaa minua sitomaan kengännauhat / maailma koostuu loputtomista velvollisuuksista / ja typeryyksistä isäni piippu muistuttaa / koukeroista kieltä se mikä ymmärretään / kasvit kasvavat kohti valoa minä kasvan kohti / valoa kasvit kiertyvät minä kierryn / solmiot kiertyvät viattomien kauloihin maailma/ on / nimeni on Alan I Turing olen 21 / luku on pyhä minä olen pyhä / solmioni koukerokuviot elävät puvuntakkini / taskussa minulla on maailma pienoiskoossa / näen kaiken pylvääni laelta seison kuin hullu / ylöspäin osoittava neula lopullinen totuus / on se että ei ole en tiedä mikä on lopullinen / totuus viini on typeryksille / se kangistaa kielen ja pään vaikka sitä ei tarvitsekaan muuhun / kuin imitaatioon kieli on lopultakin vain hauska leikki / kuten kaikki muukin sekopäinen / en pidä koirista en pidä ihmisistä muista kuin itsestäni / vanhempani eivät ole ihmisiä he ovat osa jotakin / korkeampaa ei heitä ole olemassa / kohmettuneet kasvit paljastavat suonensa huoneeni on / uringonvalon koti minun huoneeni minun kirjani minun / kaavioni on päässäni pää on kaikki ja aivot / elän aivoille aivot ovat minä ja minä olen aivot / numerot ovat kauniita kirjaimet minä olen / nimeni on Alan Turing olen 28 / olen nähnyt yhden naisen sellaista on / kirjakaupassa harmi etten ole nainen / ei niin että sillä olisi mitään merkitystä / mädätän omenia lautasella kuoropoikien ohuet kasvot / luostarin muuratut valkeat seinät kalkitut tiilikuviot mosaiikit / hiushalkeamat mikä on kaiken tarkoitus/ kenties saada lainaksi sateenvarjo jo jotta pääsisi pakoon / elämää sadetta siemenen muoto on silmän muoto / silmän muoto on kaiken perusta raskaista huokauksista / rakentuu maailma maailma kaatuu kuin korttitalo / ja kaikki räjähtää palasiksi silmä räjähtää ja lasiainen valuu / kauniille kasvoille sí kauniille kasvoillesi / si logiikka on peili peilit ovat sairaita sairaat ovat miellyttäviä / näen tulevaisuuteen eikä se miellytä minua / vaikka olen ten feet tall ah en halua unohtaa / maailmaa joka on minut synnyttänyt / haluan unohtaa ajan / nimeni on AlanT uring olen 35 / sí minulla on akustinen muisti se / pylvään laella olen Simon eivätkä / siitä ei pidetä numerot virtaavat kaikki / aavikoilla rotta kumartuu alttarille akustinen / rotta nivelhäntineen ja älykkäät koneet / haluavat olla rottia jotka se mikä on ajatus / on kone en pidä ihmisistä muista kuin / matkijarotista huokailevista raunioviiruista tornipöllön / siipien giljotiinihavinasta kirjan yllä 9 haudoissa minua / nokan kaikukammiosta numerot virtaavat ja kaikki / meriosa shakkimysteerio tornini laeilla on vain / yksi merkitys joka on kaikki joka on kone joka on ajatus/ joka on kone joka on ajatus / nimeni on alan turing olen 42 ja / metsästyshaukkojen silmät ovat peitetyt niinkuin / kasvojen puoliskot sumentuvat sulautuvat / toisiinsa muovautuvat ihokaistaleet repaleiset / papyruskailojen savuhuntu metsästyshaukan / ääni on ääneni joka leviää kaikkialle niinkuin/
} 
A relação entre a Kalevala e a poesia contemporânea de Juhana Vähänen perpassa questões relacionadas à estrutura versificada de ambas as obras, à construção de personagens, às concepções culturais finlandesas, principalmente no que tange à individualidade, e às simbologias expressas tanto na obra romântica como em Alan Turing.

A escolha de Lönnrot por narrar a Kalevala em versos relaciona-se à iniciativa romântica de legitimação nacional, recuperando muitas características da epopeia tradicional helênica, dentre as quais a estrutura versificada da narrativa. Para Georg Lukács,

Seria superficial e algo meramente artístico buscar as características únicas e decisivas da definição dos gêneros no verso e na prosa. Tanto para a épica quanto para a tragédia o verso não é o constituinte último, mas antes um sintoma profundo, um divisor de águas que lhes traz à luz a verdadeira essência da maneira mais autêntica e apropriada. (LUKÁCS, 2007, p.55).

Se, por um lado, a estrutura em versos aproxima a epopeia da poesia contemporânea, a constituição de personagens pode distanciá-las. Na epopeia helênica, o herói nunca é de fato um indivíduo e sua representação da coletividade é marcada pelo areté, isto é, "a qualidade no mais alto grau de excelência. Aquiles, o 'divino', o 'de pés ligeiros', é o paradigma da areté guerreira." (APPEL, 1992, p.37). Na epopeia romântica a coletividade se mescla à individualidade, fato expresso na própria criação do sampo, um erro de cálculo individual que vem a pôr em risco o bem-estar coletivo finlandês. Essa tendência será redimensionada por Juhana Vähänen ao ampliar traços de Alan Turing para discutir características culturais e concepções artísticas.

Além disso, a Kalevala se distancia da epopeia tradicional no que tange às aventuras de seus heróis. Nas narrativas homéricas as demandas são sempre cercadas de certezas, em um mundo de dimensões diminutas e seguras. Na construção de Lönnrot há espaço para a dúvida, fator discutido por Lukács ao afirmar que

hyönteisparvi fragmenttijoukot suunnattomat valasparvet / ragtime pianon klusterikollaasit numero/ abstraktiot leijailevat kiintopisteet konemuistoni / koodimurrostila käännösnytkähdys havainto teko ajatus / metsästyshaukan silmäpallot maailmankuviot numeromuistot / akustinen kirkaisunuoli silmäomenat/ yhdistyneet akustiset nidokset sí / sí/ 
O círculo em que vivem os metafisicamente os gregos é menor do que o nosso: eis porque jamais seríamos capazes de nos imaginar nele com vida: ou melhor, o círculo cuja completude constitui a essência transcendental de suas vidas rompeu-se para nós; não podemos mais respirar num mundo fechado. (LUKÁCS, 2007, p.30).

A Kalevala explora o território que dá nome ao poema, ou seja, a terra de heróis, antes que viesse a ser denominada Finlândia. Não há nada para além de suas fronteiras na Lapônia, mas tudo que ocorre em seu universo geográfico tem consequências para todos os seus habitantes, em uma tentativa de reproduzir o universo helênico. Em Alan Turing, o universo espaço/tempo se alarga ao se problematizar a vida de um matemático inglês que viveu em meados do século XX para discutir temas que perpassam a contemporaneidade finlandesa, incluindo aqueles que revisitam seu processo de afirmação nacional via Kalevala.

Partindo de versos da obra de Juhana Vähänen temos, por exemplo, a reinterpretação do refrão épico, com as estrofes iniciando com "meu nome é Alan Turing". Tal organização poética reitera a presença do individualismo que permeia a Kalevala, além de refletir as origens orais do poema épico, uma vez que o uso de refrões é um recurso mnemônico muito útil aos trovadores. Nessa recriação escrita ele vem marcar a passagem de tempo para o personagem central do poema, mesclando os gêneros narrativo e poético. Um paralelo interessante se dá no fato de o refrão mais comum da Kalevala dizer "Velho e justo Väinämoinen" (LÖNNROT, 2009, p.71), representando igualmente uma noção cronológica e de experiência de vida.

O refrão em questão representa, ainda, outra característica da poesia oral, na forma do extenso uso de aliterações, sendo lido em finlandês como "vaka vanha Väinämöimen". Essa característica é reinterpretada por Vähänen, por exemplo, na primeira estrofe de Alan Turing na qual lemos "ja kasvi kiertyy kuten Alan Turing kiertyy", verso traduzido em nossa reescrita como "as plantas viram e reviram Alan Turing vira e revira".

A família é tema central da Kalevala como de qualquer narrativa épica, sendo o imenso poema iniciado com o nascimento de Väinämöinen, herói maior da epopeia: " $\mathrm{E}$ Väinämöinen nasceu, / bravo poeta ancestral / veio do ventre da virgem, / Ilmatar sua mãe" (LÖNNROT, 2009, p.75). Essa característica é apresentada por Vähänen sob uma nova luz, com o cachimbo do pai lembrando o jovem Alan Turing das viradas da 
linguagem e com as recomendações da mãe de fazer coisas banais, como dar o nó nos cadarços contribuindo para a conclusão das responsabilidades e estupidezes da vida. Ao contrário de ter sua vida traçada por seus pais para se tornar um herói épico, Alan Turing reage ao mundo e às pessoas com indiferença ("não gosto de outras pessoas") e inadequação ("que pena eu não ser mulher") e tenta abarcá-lo ("eu tenho um globo / em miniatura no bolso do meu paletó") por meio da inteligência matemática e verbal (“o cérebro sou eu e eu sou o cérebro / números são lindas letras eu sou”).

A ligação entre palavras e matemática, nas "viradas e reviradas da linguagem" são representativas do materialismo linguístico de Vähänen, demonstrando uma forte contribuição da escola L-A-N-G-U-A-G-E de poesia estadunidense.

A presença da natureza é marcante na Kalevala, como é de esperar de uma narrativa épica romântica e em ambas obras há uma preferência pelas aves. Na epopeia mulheres se transformam em aves monstruosas, e uma delas é diretamente responsável pela criação do mundo, uma vez que é o ovo de uma pata que se converte no primeiro continente: "a parte de baixo do ovo / tornou-se a crosta da terra, / a parte de cima do ovo / tornou-se o domo do céu" (LÖNNROT, 2009, p.65). Em Alan Turing o albatroz, ave de mau augúrio em muitas culturas, aparece logo no início do poema, circulando sobre o ainda adolescente protagonista, e o falcão que fecha o poema reflete todo o mundo em seus olhos.

O falcão permeia, ainda, as referências à morte trágica de Turing, que podem ser notadas em "o grito do falcão / é meu grito se espalhando como / um enxame e fragmentos de hordas de baleias" e em "amarram cachos em torno dos pescoços dos inocentes o mundo / é".

Outra característica da cultura finlandesa presente na Kalevala e reinterpretada por Vähänen é o gosto pelo álcool. Na epopeia, a primeira plantação de Väinänöinen após a criação do mundo é de cevada e todos os banquetes são regados a muito vinho. Na epopeia lê-se "Então canto um bom verso, / forjando a também formosa / poesia do centeio, / a cerveja da cevada" (LÖNNROT, 2009, p.51). Hoje em dia os finlandeses cultivam o hábito de beberem muito, principalmente vodca, em curtos espaços de tempo. Alan Turing, entretanto, segue na contramão da identidade nacional finlandesa, afirmando que "vinho é para os burros / ele entorpece a linguagem ele entorpece a mente apesar de somente necessário / para a imitação da linguagem um jogo tolo”. 
Como já vimos, a identidade sexual do protagonista é abordada, mas amplamente descartada em seguida, talvez para evitar as interpretações da vida do matemático somente pelo recorte de sua orientação sexual ("que pena eu não ser mulher / não que isso signifique alguma coisa"), ainda que sua perseguição legal e período no "claustro" sejam abordados.

A memória, por sua vez, tem espaço em ambas as obras aqui discutidas, sempre associada à atividade intelectual. A Kalevala abre com os versos "Minha mente almejando / meu cérebro concebendo / começar logo a cantar" (LÖNNROT, 2009, p.43), noção que também permeia Alan Turing, com menções a "memórias acústicas" e a resolução segundo a qual "oh eu não quero esquecer / o mundo que me criou / eu quero esquecer o tempo". No momento de escrita da Kalevala a memória dos trovadores era o único elemento capaz de salvar a língua finlandesa e a identidade cultural que povoa seus cantos. Hoje a Finlândia vive um momento de entrada tardia no intercâmbio com o mundo exterior, iniciado em meados da década de 1990, levando a um dilema entre buscar referências externas, artísticas ou tecnológicas, e preservar a memória coletiva de sua insular cultura.

A religiosidade presente na Kalevala é ambígua, pois se trata de uma narrativa com inúmeras referências pagãs, editada para diminuir a credibilidade da sabedoria popular, como um passar da tocha do paganismo rural ao cristianismo urbano, representado pelo luteranismo de herança sueca. A presença do paganismo é mais sentida no início da epopeia, com a criação do mundo, com diversas referências a Ukko como "deus supremo" (LÖNNROT, 2009, p.59). Hoje em dia a Finlândia não habita nenhum dos dois cenários religiosos, sendo marcadamente secular, o que justifica imagens como "no deserto um rato se ajoelha ao altar", presentes no poema de Juhana Vähänen.

A presença de máquinas inteligentes é um elemento esperado em Alan Turing, uma vez que se trata da leitura poética da vida do matemático responsável pelo nascimento da inteligência artificial. A ligação dos finlandeses com a tecnologia é assombrosa, bastando mencionar que no país não se encontram telefones públicos e os celulares são usados até mesmo para operar lavadoras e secadoras de roupas. É possível acessar a internet ou fazer uma ligação de qualquer uma das milhares de ilhotas, muitas 
vezes desertas, do país, meio pelo qual a maior parte dos finlandeses se comunica com o mundo exterior.

Apesar da quantidade e extensão dos paralelos entre o poema Alan Turing e a Kalevala, o texto de Juhana Vähänen não é uma releitura das referências do épico nacional. As conexões quase involuntárias entre a produção poética contemporânea e a epopeia romântica são, de certa forma, reflexos da profundidade da influência da Kalevala na Finlândia, uma país fundado pela poesia.

\section{REFERÊNCIAS}

APPEL, M. B.; GOETTEMS, M. B. (Org.). As formas do épico - da epopéia sânscrita à telenovela. Porto Alegre: Movimento, 1992.

CASANOVA, P. A República Mundial das Letras. São Paulo: Estação Liberdade, 2002.

ELOVAINIO, P. Factos sobre a Finlândia. Keurru: Otava, 2003.

JAKOBSON, M. Finland: Myth and reality. Helsinque: Otava, 1987.

KLINGE, M. Breve História da Finlândia. Brasília: Escopo, s/d.

LÖNNROT, E. Kalevala: poema primeiro. Tradução e comentários de José Bizerril e Álvaro Faleiros. Ed.bilíngue. Cotia, SP: Ateliê, 2009.

LÖWY, M.; SAYRE, R. Romantismo e política. Tradução de Eloisa de Araújo Oliveira. São Paulo: Paz e Terra, 1993.

LUKÁCS, G. A Teoria do Romance. São Paulo: Ed.34, 2007.

VÄHÄNEN, J. Alan Turing. Helsingin Sanomat. Disponível em: http://www2.hs.fi/extrat/kulttuuri/kirjallisuuspalkinto05/ote_cantorin_polya.html Acesso em 11 de março de 2011.

WALTARI, M. O Aventureiro. Rio de Janeiro: Mérito, s/d.

Artigo recebido em 21/032011

Aceito para publicação em 26/06/2011 